\title{
EFFECT OF THE RATE OF COOLING ON THE MAG- NETIC AND OTHER PROPERTIES OF AN ANNEALED EUTECTOID CARBON STEEL
}

\author{
By C. Nusbaum and W. L. Cheney
}

\begin{abstract}
This paper discusses the results of a study of the effect of the rate of cooling upon the magnetic and other properties of an annealed eutectoid steel. In carrying out the experiment, six specimens of this steel were selected, heated to $800^{\circ} \mathrm{C}$, and allowed to cool at various rates-one in air, another in lime, and the remainder in the furnace at slower and slower rates. The following properties were then measured: Normal induction for ordinary and large magnetizing forces, residual induction, coercive force, resistivity, and Shore scleroscope hardness. In order to study the metallographic structure of the steel, micrographs of each specimen were made at a magnification of 500 diameters.

A study of the experimental results show that as the cooling rate is diminished there is a pronounced increase in the value of the maximum induction for a given small magnetizing force, a decided increase in the maximum permeability, but a decrease in the coercive force. The values of the coercive force agree very well with the scleroscope hardness number.

In plotting the reluctivity line as calculated from the magnetization curve, it is found that the reluctivity line consists of two straight lines with the bend occurring at a definite point. As the structure of the steel changes from an essentially sorbitic one to "divorced" pearlite, there is a gradual shifting of this bend toward the origin and a greater difference between the values of the "real" and "apparent" values of the saturation intensity of magnetization as calculated from the slopes of the reluctivity line.
\end{abstract}

\section{CONTENTS}

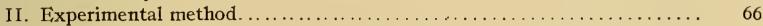

I. Material.......................................... 66

2. Heat treatment................................... 67

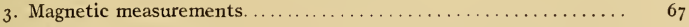

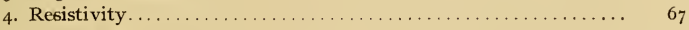

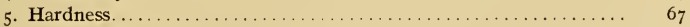

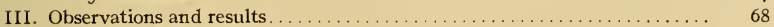

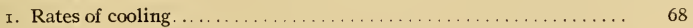

2. Magnetic properties............................. 69

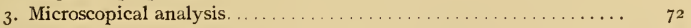

IV. Discussion..................................... 74

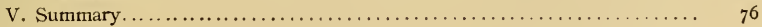
$21623^{\circ}-21$ 


\section{INTRODUCTORY}

In a previous paper ${ }^{1}$ the effect of the quenchings and subsequent tempering on the magnetic properties of a eutectoid carbon steel were presented and the metallurgical significance of these effects were discussed. Particular use was made of the magnetic reluctivity relationship. The investigation has since been extended to slower rates of cooling, some of which are within the annealing range. This investigation is discussed in the present paper.

That the physical properties and the crystalline structure of steel are greatly affected by various rates of cooling from or through the critical range is universally recognized by metallurgists. The influence of the rate of cooling on the magnetic properties is also generally recognized, yet there does not appear to be a full appreciation of its importance. In much of the published magnetic data mention is made that the steel was in the "annealed condition," but generally no information is given as to the initial temperature, the length of time the material had been kept at such temperature, or the rate of cooling. Perhaps the data of Yensen $^{2}$ on electrolytic iron and silicon steel are the most complete in this respect. The present paper is an attempt to emphasize the importance of these factors by presenting data on the magnetic and other physical properties and also on the microstructure resulting from various cooling rates.

\section{EXPERIMENTAL METHOD}

\section{MATERIAL}

The specimens were of the following chemical composition:

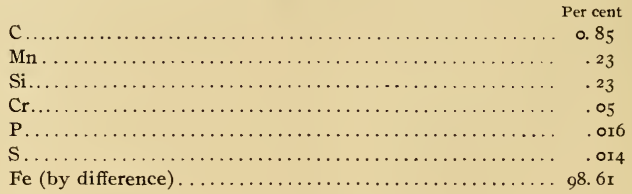

The specimens were in the form of cylindrical rods $\mathrm{I} \mathrm{cm}$ in diameter and $25 \mathrm{~cm}$ long, and had been previously heated to $800^{\circ} \mathrm{C}$ and furnace annealed.

1 Nusbaum, Cheney, and Scott, B. S. Sci. Papers, No. 404; 1920.

$2 \Upsilon$. D. Yensen, Univ. of Yllinois Engineering Experiment Station, Bull. No. 72; 1914. 


\section{HEAT TREATMENT ${ }^{3}$}

Each specimen was heated to a temperature of $800^{\circ} \mathrm{C}$ in a small Hoskins resistance furnace and kept at this temperature for a definite interval of time. The temperatures were measured by a platinum platinum-rhodium thermocouple. Oxidation of the specimens at the high temperatures was reduced by the presence of a gas flame within the furnace. Since, at the slow cooling rates, decarburization of the outer portions of the specimen becomes appreciable, all of the specimens were turned down to a diameter of $8 \mathrm{~mm}$ so that the specimens throughout their entire cross section would be uniform in properties and composition. One end of each specimen was kept for microscopic examination.

\section{MAGNETIC MEASUREMENTS}

The magnetic measurements at ordinary magnetizing forces were made with a Burrows ${ }^{4}$ permeameter. At high field values the measurements were made by a modified form of the "isthmus" method. ${ }^{5}$ For the latter measurements it was necessary to reduce the diameter of the specimens to $6 \mathrm{~mm}$.

\section{RESISTIVITY}

The resistance measurements were made by a comparison method: The "fall of potential," both across the terminals of a standard shunt connected in series with the current-carrying specimen, and across knife-edge potential terminals in contact with the specimen and $20 \mathrm{~cm}$ apart, was measured by a highresistance Wolff potentiometer. A series of alternate measurements were taken. In order to minimize the effects on the specimen of temperature changes caused by the heating effects of the current, observations were not taken until an equilibrium temperature had been reached.

\section{HARDNESS}

One end of each specimen was polished for the determination of the scleroscope hardness, and the determinations were made by a self-recording Shore scleroscope. The size and form of the specimens did not permit of Brinell hardness tests.

${ }^{3}$ The heat treatment was carried out by Messrs. H. Scott and T. G. Digges, of the heat-treating laboratory of the Bureau of Standards. Mr. Scott also gave the writers valuable assistance in selecting the most suitable cooling rates for these experiments.

1 C. W. Burrows, B. S. Sci. Papers, No. 117; 1909.

6 W. L. Cheney, B. S. Sci. Papers, No. 36r; 1920. 


\section{OBSERVATIONS AND RESULTS}

\section{RATES OF COOLING}

Such rates of cooling were chosen as to cause a gradual variation from an essentially sorbitic structure to one in which the matrix is essentially divorced pearlite. Specimen 16 was allowed to cool in air, and specimen 17 in lime, while specimens $18,19,20$,

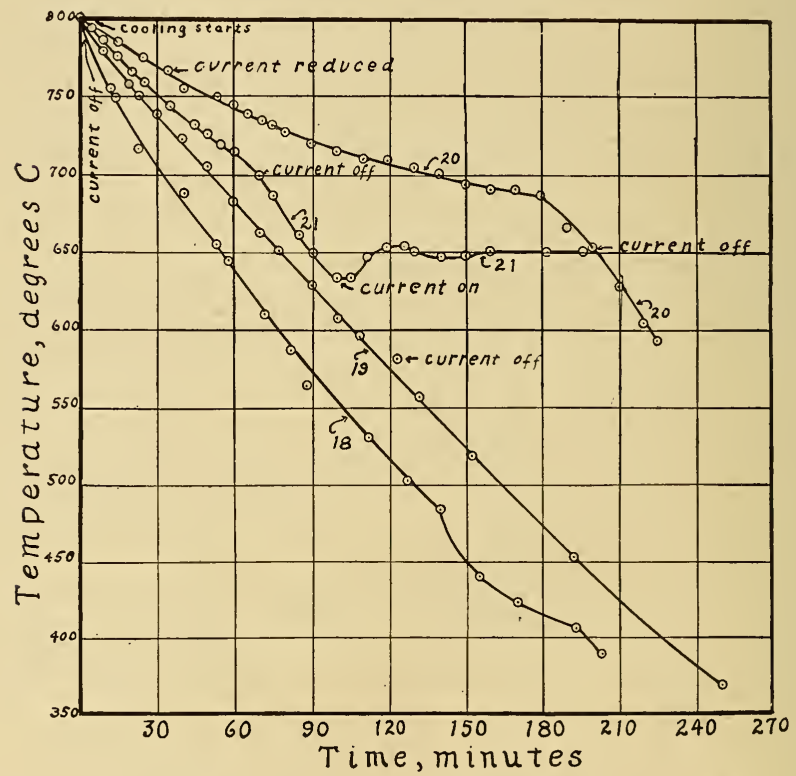

FIG. I.-Cooling curves for 4 specimens of annealed eutectoid carbon steel

and $2 I$ were furnace cooled at various rates and under different conditions. In Fig. I are plotted the time-temperature curves for the furnace-cooled specimens. In the case of specimen 18 the current was cut off after the temperature had been held at $800^{\circ} \mathrm{C}$ for $\mathrm{I} 2$ minutes, and the specimen was then allowed to cool with the furnace. Specimen 19 was held for a time interval of 13 minutes at a temperature of $800^{\circ} \mathrm{C}$, and then slowly cooled by reducing the current, which was cut off when the temperature 
had fallen to $580^{\circ} \mathrm{C}$; the specimen was then allowed to cool with the furnace. Specimen 20 was held for a period of 20 minutes at the initial temperature and allowed to $\mathrm{cool}$ in a definite manner by suitable reductions of the current. Specimen $2 I$ was cooled to $650^{\circ} \mathrm{C}$ in a definite manner and then held at this temperature for a period of 75 minutes in order to determine the effect upon the physical properties and structure of maintaining the material below its critical temperature during a given time interval. The times of cooling for the various specimens from $800^{\circ} \mathrm{C}$ to $650^{\circ} \mathrm{C}$ are recorded in Table $\mathrm{I}$.

TABLE 1.--Effect of Rate of Cooling on Magnetic and Other Properties of Eutectoid Carbon Steel

\begin{tabular}{|c|c|c|c|c|c|c|c|c|c|c|c|c|}
\hline \multirow[b]{2}{*}{$\begin{array}{c}\text { Spec- } \\
\text { imen } \\
\text { num- } \\
\text { ber }\end{array}$} & \multirow[b]{2}{*}{$\begin{array}{c}\text { Time } \\
\text { held } \\
\text { at } \\
800^{\circ} \mathrm{C}\end{array}$} & \multirow[b]{2}{*}{$\begin{array}{l}\text { Method of } \\
\text { cooling }\end{array}$} & \multirow[b]{2}{*}{$\begin{array}{l}\text { Time } \\
\text { cool- } \\
\text { ing } \\
\text { from } \\
800^{\circ}- \\
650^{\circ} \mathrm{C}\end{array}$} & \multirow[b]{2}{*}{$\begin{array}{c}\text { Mazi- } \\
\text { mum } \\
\text { per- } \\
\text { mea- } \\
\text { bility }\end{array}$} & \multicolumn{3}{|c|}{ Magnetic induction } & \multirow[b]{2}{*}{$\begin{array}{l}\text { Resid- } \\
\text { ual in- } \\
\text { duction } \\
\mathrm{H}_{\mathrm{m}} 150\end{array}$} & \multirow[b]{2}{*}{$\begin{array}{c}\text { Coer- } \\
\text { cive } \\
\text { force } \\
\mathrm{H}_{\mathrm{m}} 150\end{array}$} & \multirow{2}{*}{$\begin{array}{l}\text { Satu- } \\
\text { ration } \\
\text { inten- } \\
\text { sity of } \\
\text { mag- } \\
\text { neti- } \\
\text { zation } \\
\text { (calcu- } \\
\text { lated) }\end{array}$} & \multirow[b]{2}{*}{$\begin{array}{c}\text { Scle- } \\
\text { ro- } \\
\text { scope } \\
\text { hard- } \\
\text { ness }\end{array}$} & \multirow[b]{2}{*}{$\begin{array}{l}\text { Specific } \\
\text { resist- } \\
\text { ance }\end{array}$} \\
\hline & & & & & $\mathrm{H}=15$ & $H=150$ & $\mathbf{H}=1000$ & & & & & \\
\hline & $\begin{array}{l}\text { Min- } \\
\text { utes }\end{array}$ & & $\begin{array}{l}\text { Min- } \\
\text { utes }\end{array}$ & & Gausses & Gausses & Gausses & Gausses & Gausses & $\begin{array}{l}\text { C. g. s. } \\
\text { inits }\end{array}$ & & $\underset{\text { crohms }}{\text { Mi- }}$ \\
\hline 16. & $\ldots$ & Air cooled... & $\ldots \ldots$ & 385 & 5150 & 16100 & 20050 & 10050 & 13.4 & $\begin{array}{l}1564 \\
1520\end{array}$ & 43.3 & 0.2025 \\
\hline 17. & & Lime cooled. & & 437 & 6150 & 16300 & 20000 & 10540 & 12.4 & $\begin{array}{l}1550 \\
1500\end{array}$ & 42.3 & .2006 \\
\hline $18 .$. & 12 & $\left\{\begin{array}{l}\mathrm{F} \text { u r n a c e } \\
\text { cooled }\end{array}\right.$ & 56 & 630 & 9300 & 16100 & 20030 & 12300 & 10.18 & $\begin{array}{l}1580 \\
1490\end{array}$ & 33.0 & .1941 \\
\hline $19 .$. & 13 & $\left\{\begin{array}{c}\text { F u r n a c e } \\
\text { cooled }\end{array}\right.$ & 78 & 630 & 9300 & 16100 & 20030 & 12300 & 10.0 & $\begin{array}{l}1600 \\
1430\end{array}$ & 30.4 & .1950 \\
\hline $20 \ldots$ & 20 & $\left\{\begin{array}{c}F \text { u } \mathrm{r} \mathrm{a} \mathrm{c} \mathrm{e} \\
\text { cooled }\end{array}\right.$ & 200 & 698 & 10000 & 16300 & 20000 & 12360 & 9.2 & $\begin{array}{l}1610 \\
1430\end{array}$ & 29.9 & .1931 \\
\hline $21 \ldots$ & 13 & $\left\{\begin{array}{c}\text { F u r n a ce } \\
\text { cooled }\end{array}\right.$ & 90 & 633 & 9300 & 16100 & 20080 & 11970 & 9.2 & $\begin{array}{l}1540 \\
1400\end{array}$ & 33.6 & .1963 \\
\hline
\end{tabular}

\section{MAGNETIC PROPERTIES}

Fig. 2 gives the normal induction curves for low and medium values of the magnetizing force, and Fig. 4 gives the curves for high values. It is interesting to observe the increase in the magnitude of the induction for a given value of the magnetizing force, as the rate of cooling is varied from air cooling to slow furnace cooling. The change in the values of the induction is most marked in the magnetizing force intervals, 10 to 20 gausses, and between the rates for the lime-cooled and normal furnace-cooled specimens. The curves for specimens $I 8, I 9$, and $2 I$ practically agree throughout the entire range of the magnetizing force, and for higher values the three corresponding curves are plotted as one curve. 


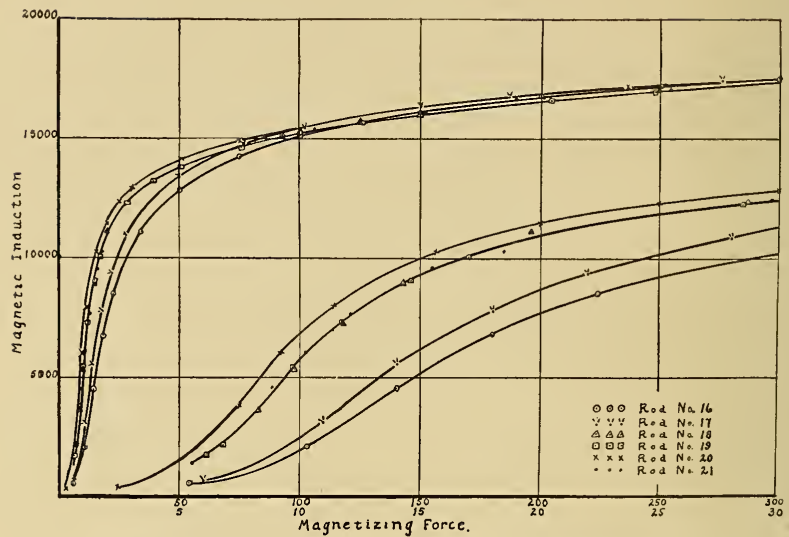

FIG. 2.-Curves showing effect of rate of cooling annealed eutectoid carbon steel upon magnetic induction for small and intermediate magnetizing forces

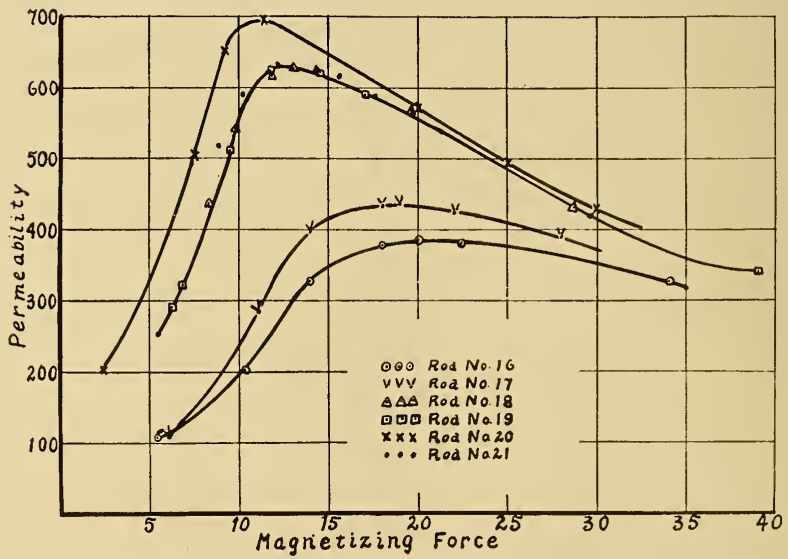

FIG. 3.-Curves showing effect of rate of cooling annealed eutectoid carbon steel upon permeability 
The relationship between the magnetizing force and the corresponding induction can, perhaps, best be noted by plotting the permeability against the magnetizing force as the independent variable, as shown in Fig. 3. Each curve passes through a maximum of increasing magnitude as the rate of cooling of the corresponding specimen decreases. A continual shifting of this maxi-

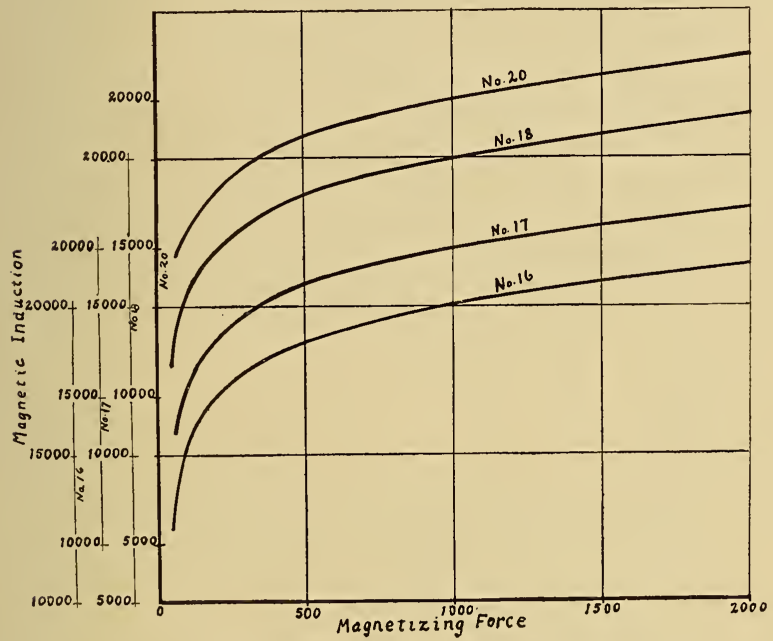

FIG. +. (urves showing effect of rate of cooling annealed eutectoid carbon stecl upon magnetic induction for large magnetizing forces

mum toward the origin is also to be noted. The values of the maximum permeability are given in Table 1 .

In Fig. 5 are plotterl for the respective specimens the reciprocals of the susceptibility, $\frac{1}{K}$, against the magnetizing force, $H$, as the independent variable. All of the curves have a quite pronounced bend in the straight-line portions of the curve. As has been shown in a previous paper, ${ }^{6}$ this bend is due to the presence of a magnetically harder constituent, the cementite in the form of conglomerate, stratified, or "divorced" masses. The reciprocal of the slope of the lower straight-line portion of the curve is pro- 
portional to the "apparent" maximum intensity of magnetization, while the reciprocal of the slope of the upper part of the straightline portion of the curve is proportional to the "real" maximum intensity of magnetization of the material for the particular arrangement of the constituents. Both the apparent and real saturation values are given in Table 1 . Attention is called to the

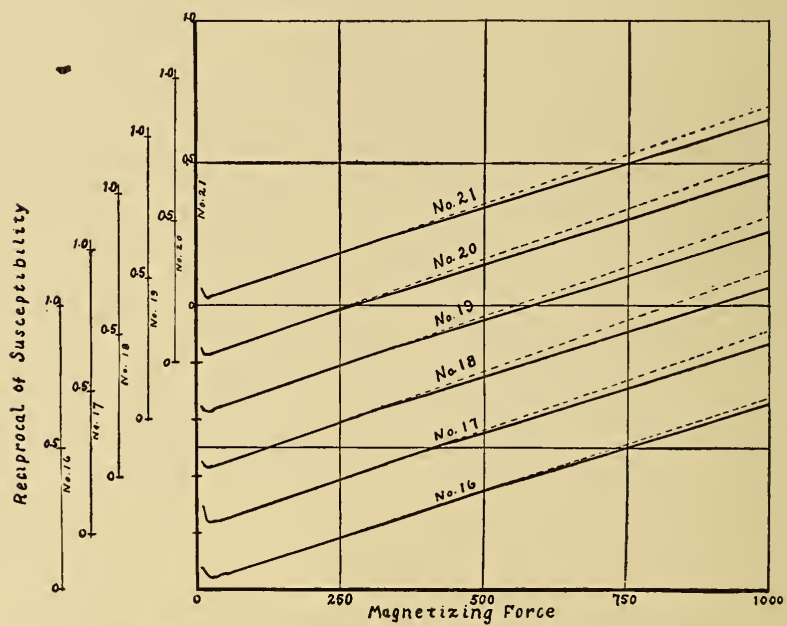

FIG. 5.-Curves showing effect of rate of cooling annealed eutectoid carbon steel upon reciprocal of susceptibility

gradual shift of the bend in the curves toward lower values of the magnetizing force with decreasing values of the rate of cooling.

\section{MICROSCOPICAL ANALYSIS}

The micrographs of Figs. 6 to $1 \mathrm{r}$, inclusive, all at a magnification of 500 diameters, represent the average structural condition shown by etching for ro seconds in 5 per cent alcoholic picric acid. The difference between the furnace-cooled, the air-cooled, and the lime-cooled specimens is very marked. The air-cooled material (specimen 16 , Fig. 6) consists largely of sorbite with intervening patches of coarse pearlite. In these patches "free" ferrite is seen

7 This analysis was made by H. S. Rawdon, chief of the metallographic laboratory of the Bureau of Standards, to whom the writers are greatly indebted for his painstaking work. 


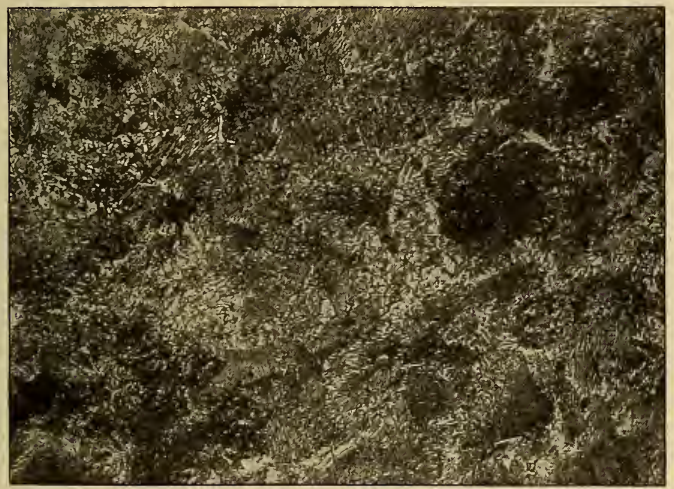

FIG. 6.-Micrograph of specimen 16 , cooled in air from $800^{\circ} \mathrm{C}$

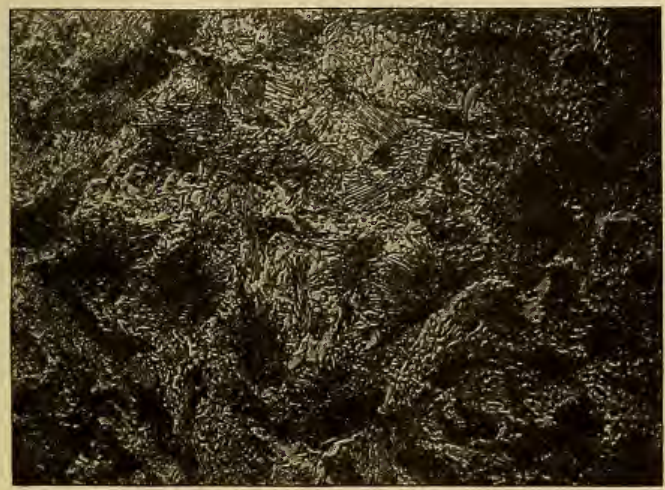

FIG. 7.-Micrograph of spcimen $\mathrm{I7}$, cooled in lime from $800^{\circ} \mathrm{C}$ 
to exist, often in masses of considerable size. The effect of the slow cooling in lime (specimen 17 , Fig. 7) was to allow most of the grains, sorbitic when air cooled, to form as lamellar pearlite. The patches of coarse pearlite with the conspicuous free ferrite still persist after cooling in lime.

The four specimens (Nos. $I 8, I 9,20$, and 21 , Figs. 8, 9, I0, and II), cooled slowly in the furnace, are very similar in structure. Patches of lamellar pearlite were found in the structure of each, the amount decreasing somewhat as the rate of cooling of the specimen was decreased. The matrix of the material in each case (specimens $I 8, I 9,20$, and $2 I$ ) consists largely of divorced pearlite; that is, cementite particles in a matrix of ferrite. The size of the cementite particles increases somewhat as the rate of cooling of the specimen is decreased.

\section{DISCUSSION}

The magnetization curves for specimens $I 8$ to $2 I$, inclusive, are quite characteristic of magnetic materials in the annealed condition. This is indicated by the comparatively high values of the maximum permeability. The results obtained are similar to those of Yensen ${ }^{8}$ on electrolytic iron melted in vacuo. In his experiments much slower rates of cooling were used. However, the effect of magnetizing forces of 15 gausses in the eutectoid steel is more pronounced than for corresponding rates of cooling in pure iron. This effect is evidently due to the influence of the cementite in the resulting sorbitic and pearlitic structures acting both as a magnetically harder medium and as a retarding agent for the transformation from gamma to alpha iron. The first of these is more likely the predominant factor.

The experiments of Howe ${ }^{9}$ show a quite definite relationship between the logarithm of the time of cooling from 800 to $60^{\circ} \mathrm{C}$ and the resulting structure of a eutectoid carbon steel. While the results here presented show no mathematical relationship between the cooling rates and the magnetic constants, there is, however, a marked correspondence. The maximum induction increases or decreases directly, and the coercive force, inversely, with the time of cooling from 800 to $650^{\circ} \mathrm{C}$. The residual induction does not show as marked a relationship. Since both the magnetic constants and the metallographic structure are in-

${ }^{8}$ T. D. Yensen, Univ, of Illinois Engineering Experiment Station Bull. No. 72; 1914

${ }^{9}$ Howe and Levy, Jour. Iron and Steel Inst, 94, pp. $210-232 ; 8916$. 


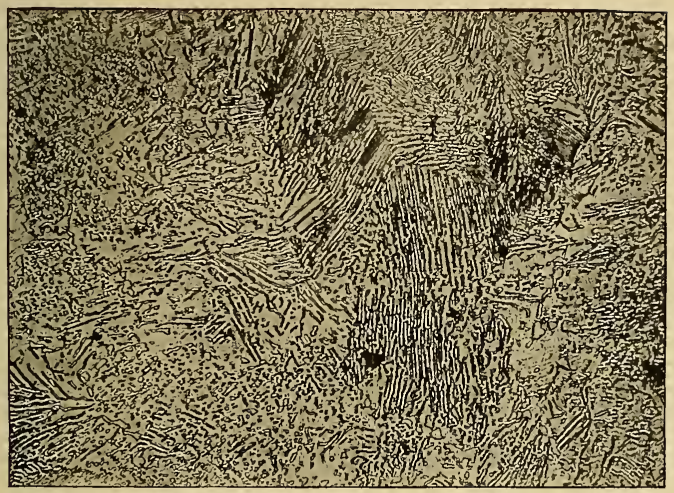

FIG. 8.-Micrograph of specimen 18 , cooled in furnace from $800^{\circ} \mathrm{C}$

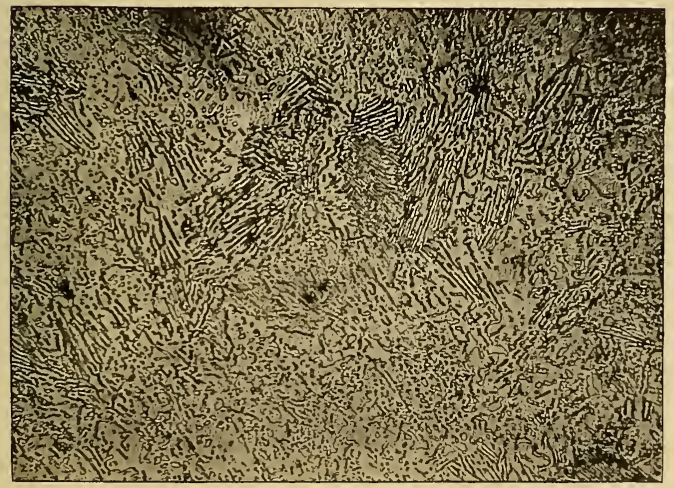

Fig. 9.-Micrograph of specimen 19 , cooled slowly in furnace from $800^{\circ} \mathrm{C}$ 
fluenced by the rate of cooling, these constants should be useful in the application of magnetic tests for determining the quality and structure of steel.

As already stated, the break in the reluctivity line increasingly shifts toward the origin with slower cooling rates. In the aircooled specimen, where the structure consists largely of sorbite with intervening patches of coarse pearlite, the break occurs at the highest value of the magnetizing force. As the material is allowed to cool at various rates so as to form a gradation in structure from sorbite to divorced pearlite, the break is shifted toward lower values of the magnetizing force. There is also a greater difference between the real and apparent maximum intensity of magnetization. In specimens 18,19 , and 21 , where patches of lamellar pearlite exist, the shifting of the break toward the origin is still more pronounced, all of the breaks occurring at approxi mately the same magnitude of the field values. There is also the largest difference between the real and apparent values of the maximum intensity of magnetization. The break in the reluctivity line occurs at the lowest field value in specimen 20 , where the pearlite is most completely divorced. For a more complete degree of "divorcing" (the "spheroidal" state) the break would probably occur at still lower values of the magnetizing force. This shifting is very likely due not only to changes in the magnetic properties of the ferrite matrix, one of the magnetic constituents, but also to the change in the flux distribution produced by the change in the arrangement of the cementite relative to the ferrite.

The scleroscope hardness and the resistivity as related to the cooling rates are interesting and significant. There is also a quite definite relationship between the coercive force and the scleroscope hardness, except for specimen 21 , which was maintained at $650^{\circ} \mathrm{C}$ for a definite time. It should be remembered, however, that the scleroscope measures essentially a property of the material quite near the surface, while the coercive force is a property of the material as a whole.

\section{SUMMARY}

In this paper are presented data showing the influence of various rates of cooling on the magnetic and other physical properties and the resulting metallographic structure of a eutectoid carbon steel. The results may be briefly summarized as follows: 


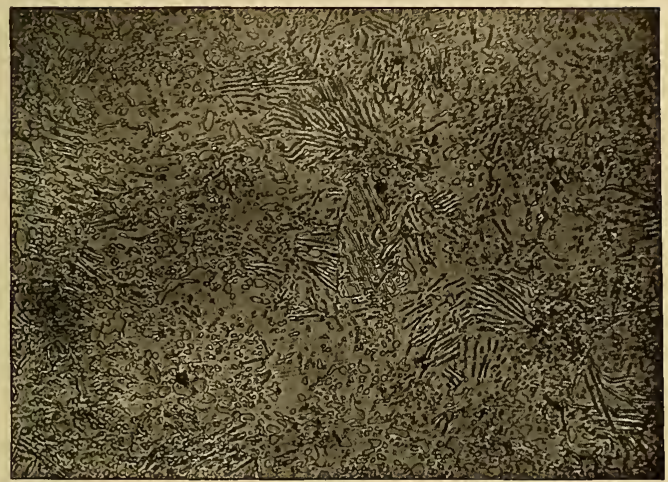

FIG. 10.-Micrograph of specimen 20 , cooled slowly in furnace from $800^{\circ} \mathrm{C}$

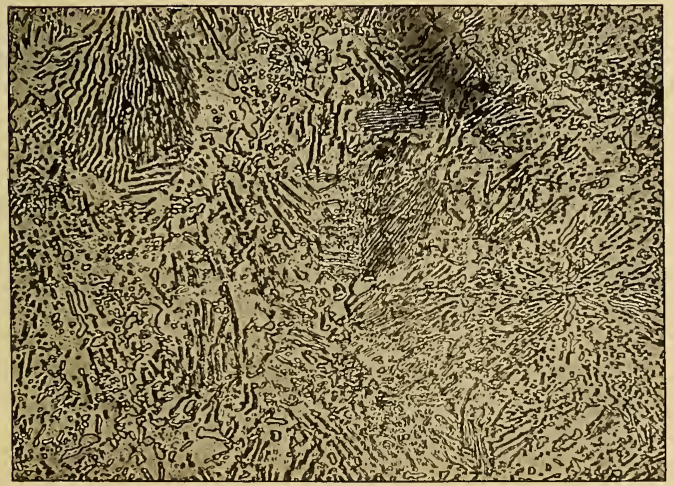

FIG. II.-Micrograph of specimen $2 I$, cooled slowly in furnace from $800^{\circ} \mathrm{C}$ and held at $650^{\circ} \mathrm{C}$ for definite period of time 
I. With decrease in the cooling rate there is a marked increase in the value of the maximum induction for a given value of the magnetizing force, an increase in the magnitude of the maximum permeability, and a decrease in the magnitude of the coercive force.

2. As the structure is changed from an essentially sorbitic one, through lamellar pearlite to divorced pearlite, there is a gradual shifting of the break in the reluctivity line toward the origin. Also the difference between the magnitudes of the real and apparent values of the maximum intensity of magnetization is greatest when the structure is that of lamellar pearlite.

3. There is a marked agreement between the values of the coercive force and the scleroscope hardness, as influenced by the various cooling rates, except when the specimen is held at a temperature of $650^{\circ} \mathrm{C}$ for a definite time.

WASHington, October 20, 1920. 